individual applicants, it must try to identify areas of promise in which research satisfies the dual criteria of desirability and practicability. Its latest attempt at crystal-gazing is a report ${ }^{1}$ by a specialist subcommittee on gastroenterology, where research is burgeoning after years of neglect. Obtaining funds for gastrointestinal research is notoriously difficult-piles and bellyache generally provoke little enthusiasm among potential philanthropists. This poverty led to the establishment of the British Digestive Foundation, now slowly and with difficulty beginning to raise money, and it seems a pity that the subcommittee's first conclusion is that MRC support should continue at the present level rather than be increased. Nevertheless, the report has been published to allow comment before the MRC formulates its policy, so that gastrointestinal scientists would do well to concentrate their minds on it.

Hitherto much gastrointestinal research has been clinical rather than basic, says the subcommittee; but this is surely a reflection of the concern of British doctors with the overwhelming quantity of fascinating clinical problems and of the comparatively recent advent of measurement rather than clinical speculation in dealing with them. For this reason it was in gastroenterology that the controlled clinical trial particularly showed its early value. Gastroenterology now stands where cardiology did in 1941 when Cournand first passed his intracardiac catheter, and the MRC is right in wanting alimentary researchers to move from the bedside to the laboratory as cardiologists did 25 years ago.

The specific areas recommended for support appear to have been chosen sometimes because methods are available, sometimes because they offer hope of success, and sometimes because the clinical problem is common and serious but as yet unsolved. Critics might say that the choice of topics, with their emphasis on peptic ulceration and gastrointestinal hormones, unduly reflects the interests of the subcommittee's two Council members, Sir Andrew Watt Kay and Professor R A Gregory. But both topics satisfy all three criteria for inclusion, and if the problems of mucosal cell resistance, the role of mucus, and the causative and protective action of hormones could be elucidated mankind would be enormously benefited. (Sir Andrew may have cast a nostalgic backward glance at the comment that gastric acid secretion has had its day as a research topic.) Practical, therapeutic yields from inmunological research, another chosen sphere of activity, are likely to be slower, but its relevance to liver disease, inflammatory bowel disease, and coeliac disease is so obvious as to justify support. Fashionable fibre and its related (or not) bacteria obtain honourable mention, and a strong hint that studies on fibre need tighter control seems justified. On pancreatic disease and psychiatric aspects of gut disorders the subcommittee's inspiration weakens, and here we seem likely to remain bedfast rather than bench-bound.

Out of favour are isolated organ techniques (perhaps not if used to study cell turnover, endocrine effects, or mucus) and pressure measurements without additions such as electromyography, while controlled trials of surgery are thought best left to the NHS.

The report deals with tactics rather than strategy, though links with basic scientists and more training in laboratory techniques for young clinicians are often stressed. Long-term grants and support to basic science departments are thought desirable, but a single opaque sentence leaves the future of special MRC units unclear.

How far this report will influence the direction of gastrointestinal research is uncertain, but it is an authoritative signpost. Those actively engaged in the specialty must now comment, and public discussion is as much to be encouraged as private correspondence. Is mucus more important than acid ? Do gut electromyograms tell us more than intraluminal pressures? Is the endocrinology of the duodenum likely to be more rewarding than isclating a living organ and studying one of its functions without interference from numerous factors? The debate is open.

${ }^{1}$ Research in Gastroenterology. Report of a Medical Research Council SubCommittee 1975. London, HMSO, 1975.

\section{Systolic murmurs in the elderly}

The belief that systolic murmurs are generally benign in elderly patients has recently been challenged by Griffiths and Sheldon ${ }^{1}$ from a survey of one-third of the old people living in a particular area. Such murmurs were common, they found, the incidence rising from $33 \%$ in the age range $60-64$ to $57 \%$ in the over $85 \mathrm{~s}$; at all ages they were more frequent in women. Moreover, in $92 \%$ of the patients with a murmur this could be related to congestive cardiac failure, ischaemic heart disease, an abnormal rhythm (atrial fibrillation; supraventricular tachycardia; or heart block; but not occasional ectopic beats, which were disregarded), peripheral vascular disease, or anaemia.

Yet perhaps the original case they set out to examine had been slightly overstated. The study quoted as evidence that aortic systolic murmurs in the elderly are benign specifically excluded patients with well-recognised valvular disorders; did not use that expression "benign"; and was at pains to point out that, even if loud, such murmurs might be due to thickening of aortic valve cusps from degenerativechanges without any important degree of stenosis: an early peak to the ejection (diamond-shaped) murmur on phonocardiography supported this suggestion. ${ }^{2}$

Pathological studies indicate that the high incidence of systolic murmurs in the elderly is related to one or more abnormalities in the left heart valves. ${ }^{3}$ Griffiths and Sheldon found that aortic murmurs were more frequent than mitral murmurs ( $75 \%$ and $12 \%$, respectively). It may be difficult to differentiate aortic and mitral systolic murmurs, ${ }^{4}$ and in one series $27 \%$ of patients thought to have aortic murmurs were found to have mitral disease at necropsy. ${ }^{5}$ In the few necropsies carried out in this survey no mitral abnormalities were found in patients thought in life to have aortic murmurs. Pomerance ${ }^{6}$ has emphasised how frequent multiple cardiac abnormalities are in the elderly. In her series of 376 patients mitral ring degeneration was found in over $25 \%$ and aortic cusp disease without stenosis in over $20 \%$-while calcified aortic stenosis, rheumatic type valve disease, and bacterial or non-bacterial endocarditis were each found in only $5 \%$ or less of the patients.

The pathogenesis of aortic valve disease in the elderly differs from that found in earlier life. Postinflammatory rheumatic lesions, giving a central circular or triangular orifice, are less frequent and degenerative calcification more common. This may affect a previously bicuspid valve giving a crescentic opening (typically in men aged 65-75) or a previously normal valve giving a triradiate orifice (especially in women aged over 75$).{ }^{36}$ Presumably it was the early stages of this process which led to the conclusion that aortic systolic murmurs in the elderly may not indicate serious stenosis. ${ }^{2}$ Calcifi- 
cation of the mitral valve ring is frequent over the age of 70 , especially in women, and may produce mitral incompetence from rigidity or distortion of the valve ring. The necropsy evidence is that this lesion is the commonest valve disturbance associated with systolic murmurs in the elderly. ${ }^{3}$ Mucoid degeneration of the mitral valve producing prolapse of a cusp is not uncommon in this age group ${ }^{3}$ and may produce its characteristic physical signs of a mid-systolic click and late systolic murmur.

In the management of the patient it is not the presence of a murmur but the underlying disturbance which is important. Severe anaemia should be corrected and any arrhythmia properly controlled. A murmur occurring only during attacks of supraventricular tachycardia or uncontrolled atrial fibrillation is probably of little importance, but symptomatic heart block will require pacing and any murmurs associated with the large stroke volume of bradycardia will then disappear. The multiple but mostly minor pathological abnormalities giving rise to a systolic murmur in the elderly may contribute to congestive cardiac failure, and effective treatment of this will eliminate murmurs due to functional tricuspid or mitral incompetence. Finally, while the authorities agree that severe aortic stenosis is an unusual cause for a systolic murmur in the elderly, the progress of this lesion is so serious that age should not in itself be regarded as a contraindication to valve replacement.

1 Griffiths, R A, and Sheldon, M G, Age and Ageing, 1975, 4, 99.

2 Bruns, D L, and van der Hauwaert, L G, British Heart fournal, 1958, 20, 370.

3 Pomerance, A, British Fournal of Hospital Medicine, 1974, 245.

4 Burch, G E, and Phillips, J H, American Heart fournal, 1963, 66, 439.

5 Pomerance, A, British Heart fournal, 1968, 30, 687.

6 Pomerance, A, British Heart fournal, 1972, 34, 569.

\section{Patients or criminals?}

The medical care of offenders against the criminal law has been bedevilled by a misconception, widely held among the judiciary and the legal profession as well as the general public, that anyone with a recognisable mental disorder must necessarily be "a suitable case for treatment." If the Report of the Committee on Mentally Abnormal Offenders, published last week, ${ }^{1}$ does nothing else it should dispel that notion for good. By no means all mental abnormality is treatable, and only a tiny proportion of patients with mental disorders can ever finally be pronounced as cured. Further, the report emphasises early on that just because someone who commits an offence can be shown to be suffering from some degree of mental disorder is no reason to assume that the condition and the act are connected-and it follows that cure of the mental disorder may have no effect on the commission of further offences.

Much of the public anxiety that led to the setting-up of Lord Butler's committee stemmed from a succession of cases in which individuals, sometimes convicted of offences, sometimes not, but known to be dangerous, were released from hospital or discharged themselves from treatment and then committed violent acts. Over the last 20 years the growth of the "open door" policy of psychotherapeutics has led to an irreconcilable gulf between the treatment available in most NHS hospitals and the needs of society-as shown by the article by Dr Paul Bowden at p 94; for there are non-offender patients as well as convicted criminals with mental disorders who require treatment or confinement in conditions of security for the safety of the public. ${ }^{2}$ A single institution cannot-as we have emphasised ${ }^{3}$ repeatedly - set out to be a therapeutic community and at the same time have the security of a prison.

Much of the committee's time was spent struggling with the problems posed by offenders with psychopathic personality disorders. It was not impressed with the results obtained by specialist psychiatric treatment centres on the Continent. "The great weight of evidence presented to us," says the report, "tends to support the conclusion that psychopaths are not, in general, treatable, at least in medical terms." From this conclusion follows a recommendation that hospital treatment orders should be made for psychopathic offenders only when there are grounds for expecting some therapeutic success. What is needed for the mass of offenders with personality disorders manifesting themselves as antisocial behaviour, the committee suggests, is a new type of secure unit with a treatment policy based on work and training; and it recommends setting up two such units so that comparisons may be made of the results of alternative policies.

Dangerous offenders who are unlikely to respond to medical treatment pose difficult ethical problems-as the committee recognises. At present there is a legal obligation to release such individuals at the end of their sentences if - as is generally the case-they are not acceptable or suitable for medical care. The committee rejects the suggestion that such dangerous offenders should be picked out while serving their sentences and recategorised as needing indefinite detention in the interests of public safety: for it is a fundamental principle of justice that any special provisions to protect society against the premature release of dangerous mentally disordered individuals should be applied at the time of sentencing and by the sentencing court. The report proposes, therefore, a new form of sentence for dangerous offenders who, while presenting a history of mental disorder, cannot be compulsorily admitted to a mental hospital, but who should not receive a life sentence. The reviewable sentence proposed would be reassessed every two years and, even if a change in the offender's mental state seemed to justify his release, he would remain under compulsory supervision after his discharge.

The report makes detailed proposals for reform of the present arrangements for examination of prisoners awaiting trial and for the aftercare of hospital patients and released prisoners, and in particular recommends the establishment of an independent advisory board which would examine all proposals referring to patients subject to special restrictions under section 65 of the Mental Health Act-those requiring the consent of the Home Secretary to their discharge or transfer from one institution to another. The committee also recommends that special revenue allocations should be made for the running costs of the regional security units proposed in its interim report $^{3}$ to supplement the secure hospitals.

Such a vast report will take time to digest-and no doubt there will be delays in carrying out its proposals. Doctors concerned with forensic psychiatry will, however, be reassured and relieved to see that at last there has been a clear, official recognition of the fact that hospitals should not be asked to attempt the care of individuals who neither want nor are likely to respond to any form of treatment offered.

\footnotetext{
${ }^{1}$ Report of the Committee on Mentally Abnormal Offenders, chairman Lord Butler, Cmnd 6244. London, HMSO, 1975.

2 British Medical fournal, 1974, 1, 527.

${ }^{3}$ British Medical fournal, 1974, 3, 215.
} 